\title{
Identifying Spatial and Temporal Variations in Concrete Bridges with Ground Penetrating Radar Attributes
}

\author{
Vivek Kumar $^{1, *(\mathbb{D} \text {, Isabel M. Morris }}{ }^{2}$ (D), Santiago A. Lopez ${ }^{2}$ and Branko Glisic $^{1}$ (D) \\ 1 Department of Civil and Environmental Engineering, Princeton University, Princeton, NJ 08540, USA; \\ bglisic@princeton.edu \\ 2 Department of Civil and Environmental Engineering, New Mexico Institute of Mining and Technology, \\ Socorro, NM 87801, USA; isabel.morris@nmt.edu (I.M.M.); santiago.lopez@student.nmt.edu (S.A.L.) \\ * Correspondence: vivekkr1809@gmail.com
}

Citation: Kumar, V.; Morris, I.M.; Lopez, S.A.; Glisic, B. Identifying Spatial and Temporal Variations in Concrete Bridges with Ground Penetrating Radar Attributes. Remote Sens. 2021, 13, 1846. https://doi.org/ $10.3390 /$ rs13091846

Academic Editor: Mercedes Solla, Vega Perez-Gracia and Simona Fontul

Received: 30 March 2021

Accepted: 30 April 2021

Published: 9 May 2021

Publisher's Note: MDPI stays neutral with regard to jurisdictional claims in published maps and institutional affiliations.

Copyright: (c) 2021 by the authors. Licensee MDPI, Basel, Switzerland. This article is an open access article distributed under the terms and conditions of the Creative Commons Attribution (CC BY) license (https:/ / creativecommons.org/licenses/by/ $4.0 /)$.
Abstract: Estimating variations in material properties over space and time is essential for the purposes of structural health monitoring (SHM), mandated inspection, and insurance of civil infrastructure. Properties such as compressive strength evolve over time and are reflective of the overall condition of the aging infrastructure. Concrete structures pose an additional challenge due to the inherent spatial variability of material properties over large length scales. In recent years, nondestructive approaches such as rebound hammer and ultrasonic velocity have been used to determine the in situ material properties of concrete with a focus on the compressive strength. However, these methods require personnel expertise, careful data collection, and high investment. This paper presents a novel approach using ground penetrating radar (GPR) to estimate the variability of in situ material properties over time and space for assessment of concrete bridges. The results show that attributes (or features) of the GPR data such as raw average amplitudes can be used to identify differences in compressive strength across the deck of a concrete bridge. Attributes such as instantaneous amplitudes and intensity of reflected waves are useful in predicting the material properties such as compressive strength, porosity, and density. For compressive strength, one alternative approach of the Maturity Index (MI) was used to estimate the present values and compare with GPR estimated values. The results show that GPR attributes could be successfully used for identifying spatial and temporal variation of concrete properties. Finally, discussions are presented regarding their suitability and limitations for field applications.

Keywords: structural health monitoring; ground penetrating radar; attribute analysis; in situ material property; machine learning; maturity method

\section{Introduction}

A significant proportion of the United States' infrastructure has exceeded its intended service life [1]. ASCE's 2021 report-card on the state of US infrastructure grades bridges at $\mathrm{C}$ with approximately $7.5 \%$ of the assessed bridges classified as structurally deficient, with $42 \%$ of the total bridge stock being over 50 years old [2,3]. To extend the remaining useful life (RUL) of these structures, structural health monitoring (SHM) and nondestructive evaluation (NDE) techniques are used by engineers. SHM can be considered as a set of processes that are aimed at providing actionable information to the stakeholders using various monitoring strategies [4]. The monitoring could be permanent or periodic to evaluate mechanical, physical, and chemical parameters over multiple scales (material or structural). Various monitoring strategies based on strain, vibration, deflection, electrical impedance, and pulse velocity in a medium have been commonly employed for SHM of transport infrastructure. Their use for regular condition assessment of transport infrastructure [5-10] has increased to reduce the total life-cycle cost of the structure [11-14].

Estimation of in situ material properties is key to these infrastructure assessment steps. These properties provide key data which form the basis for structural computations, includ- 
ing those regarding safety, remaining capacity, and actual maintenance needs. Between SHM and NDE, NDE is favored for evaluation of existing structures as these techniques can be quickly deployed and often do not require information about the structure's prior history, which can only be available if SHM systems were installed from the time of construction. SHM systems can often act as a complementary source of information to the NDEs if installed later.

NDE for transport infrastructure involves techniques to examine and qualify the structural condition of bridges, pavements, and roads without modifying the structure. Development of reliable non-destructive techniques has been the focus of research in the last few decades $[15,16]$ and some methods have been standardized by technical committees through organizations such as International Union of Laboratories and Experts in Construction Materials, Systems, and Structures (RILEM), The American Concrete Institute (ACI), and American Society for Testing and Materials (ASTM). Methods such as acoustic emissions [17-19], thermal methods [20,21], ultrasonic [22-27], magnetic methods [28,29], vibrational analysis [30,31], rebound hammer [32], combined methods such as SonReb [33,34], and ground penetrating radar (GPR) [35-38] have been popular. These approaches focus on estimating the current strength levels of structural members, estimating the moisture content, predicting damage due to corrosion, and detection of cracks $[39,40]$. Often a single NDE method does not provide reliable estimates of these parameters and data fusion techniques are employed to converge towards a better estimate [40-44]. In this paper, GPR is used as a nondestructive evaluation technique for comprehensive assessment of concrete structures. GPR enables the inspectors to rapidly cover large surfaces without disrupting the traffic, saving on time and expenses required for performing such evaluations.

GPR-based condition assessment has gained great traction over the last two decades $[7,45]$ and has become one of the most successful NDE approaches for investigation of transport infrastructure such as bridges and pavement [6]. In the GPR approach, low-frequency short electromagnetic signal pulses ( $\leq 1 \mathrm{~ns})$ are emitted from the transmission antenna on the surface and the subsequent reflections are recorded at virtually the same location on the surface by the receiving antenna. The recorded signal is called an A-scan (or trace) and is a time-series of the reflected amplitude. Most surveys consist of a series of adjacent A-scans collected along a transect, forming a B-scan or profile. The high spatial resolution and sensitivity of the electromagnetic signal to factors such as electrical conductivity and moisture content make GPR particularly useful for feature detection and visual inspection of concrete structures [46]. They have been used for location of reinforcements and tendon ducts [46-48], voids [49], determination of concrete cover thickness [45], delamination, and crack detection [50]. Concrete moisture content [51,52] and pavement density [53] are other application areas of GPR-based condition assessment using amplitude of the signal as the quantifying parameter to estimate material properties.

Even though the use of GPR has gained prevalence, GPR attributes are rarely used for infrastructure assessment. In previous work by the authors, GPR attributes were successfully employed for estimating the material properties (compressive strength, porosity, density) of concrete [54]. Previous works by the authors' research group focused on feasibility of identifying material features in concrete deck using GPR attributes and quantitative estimation of concrete properties in laboratory conditions. The current work extends the previous studies to estimate relative variations in material properties using GPR attributes in real-life conditions. Attribute analysis is chosen in this work too as it is computationally inexpensive and does not require knowledge of the physical structure. As such it can efficiently and effectively be applied to buildings, bridges, pavements, and highways. Commonly used attributes in civil engineering applications include transient and time lapse attributes, imaging analysis such as coherence, and amplitude- and frequency-based attributes such as energy and frequency spectra $[47,55]$.

The objective of the paper was to use GPR attributes to identify spatial and temporal variations in concrete properties. This would enable both qualitative and quantitative 
assessment of concrete bridges for both monitoring and inspection needs. To achieve this aim, GPR scans on a concrete pedestrian bridge are collected. These scans are used to obtain attributes which provide qualitative differences and indicate the spatial variability of concrete strength of the bridge deck. Using the machine learning models that predict physical concrete properties from GPR attributes developed by the authors in a previous work [54], quantitative assessment of the bridge deck is carried out. These quantitative assessments involve using GPR attributes to estimate in situ material properties of concrete, such as density, porosity, and compressive strength and establishing the differences over both spatial and temporal domain. One of the challenges of using approaches such as GPR is the lack of calibrated data about these properties to verify the results; in this work, a variety of other data sources and analyses are used to provide some validation. Compressive strength values estimated by GPR attributes were compared with the strengths of the reserved core samples to validate the proposed approach. Since the bridge was instrumented with a fiber-optic SHM system, available temperature measurements are used to determine the present compressive strength using maturity index and compared with the compressive strength estimated using GPR attributes for control.

\section{Data Description}

In this section, the data collection and processing applied for the GPR attribute-based inspection of concrete bridges are described. For the purposes of establishing the use of GPR as an approach to identify the spatial and temporal variations in concrete, four different types of data sets were used. Three of these data sets have been published in previous works by SHMlab and are being used as is $[47,54,56]$ and the fourth is the GPR scan collected on a real-life bridge for this study. Interested readers can refer to the cited works for more details. These three data sets are:

1. Laboratory data: Concrete cylinders of 3in diameter and 6in height as per ASTM testing standards, and beams $(15 \times 15 \mathrm{~cm} \times 90 \mathrm{~cm})$ made of various industrial mixes and cured under different conditions were fabricated and tested. Direct tests were used to obtain values for density, porosity, and compressive strength and the corresponding beams were scanned using a 900-MHz GSSI antenna. The direct test values and calculated attributes from scans were used to develop machine learning models to predict the material properties on Streicker bridge in Section 4. The details of data collection can be found in the previous work by the authors [54]; the lab data and connection with the modeling pipeline (Section 3) are summarized in Figure 1.

2. Streicker bridge: Streicker bridge at Princeton University is the real-life application structure for this paper. The pedestrian bridge provides strategic connection between the east and west ends of the campus. It is a post-tensioned prestressed bridge in the shape of a chromosome. It is $105 \mathrm{~m}$ long and consists of a $35 \mathrm{~m}$ deck-stiffened arch (the main span) and four approach legs. The approach legs are continuous curved concrete girders. The front view of the bridge is shown in Figure 2. The main span and all legs except the southeast leg were constructed in August 2009. The southeast leg was constructed in October of that year using the same specified concrete mix (Class A HPC with design strength of $41 \mathrm{MPa}$ at 28 days).

Streicker bridge was instrumented with long-gage fiber optic sensors at the time of construction for research and teaching purposes. A schematic of Fiber Bragg Grating (FBG) sensor used for temperature monitoring is shown in Figure 3. A brief description of the working is as follows: When a light is sent from the reading unit, specific wavelengths of the light are reflected back by the Bragg gratings in the fiber. Depending on the strain in the fiber, the reflected wavelength changes. The fiber optic sensors installed in Streicker bridge measure both the temperature and strain.

The sensor locations along the main span and southeast leg are shown in Figure 4 by black boxes. The sensors have been continuously monitoring strain and temperature with periodic interruptions for maintenance since their installation in 2009. These sensors are installed at various locations on the bridge which provide the temperature 
data that are required for the maturity index calculations. The temperature readings have an uncertainty of $0.14{ }^{\circ} \mathrm{C}$. These sensors are used for compressive strength calculations based on the maturity method. Two typical locations are also highlighted in Figure 4. The GPR attributes collected on Streicker bridge in 2016 and 2020 are used to identify the spatial and temporal variation in concrete in a structure. There are two types of data sets used from previous studies for validation of those predicted values:

(a) Temperature measurements: Streicker bridge is instrumented with Fiber Bragg Grating (FBG) fiber-optic sensors which have been regularly collecting temperature and strain data from the time of construction in 2009. The sensor locations along the main span and southeast leg are shown in Figure 4 by black boxes. The sensors have been continuously monitoring strain and temperature with periodic interruptions for maintenance since their installation in 2009. These sensors are installed at various locations on the bridge which provide the temperature data that are used for the maturity index estimates of compressive strength. The temperature readings have an uncertainty of $0.14{ }^{\circ} \mathrm{C}$. The location of the typical sensors in the main span (P8h9) and southeast leg (P10h11) are highlighted in Figure 4.

(b) Core reserves: Class A HPC concrete with a design strength of $41 \mathrm{MPa}$ (at 28 days) was used for the construction of the bridge. The bridge was constructed in two phases; one in August 2009 (main span and northeast leg included) and the other in October 2009 (southeast leg). Even though the design strengths were the same for the two construction phases, the measured compressive strength on the reserved cores indicate a nominal compressive strength of $51 \mathrm{MPa}$ for the main span (MS) and northeast (NE) leg and $59 \mathrm{MPa}$ for southeast (SE) leg at 28 days [56]. Figure 5 shows the compressive strengths of the reserved cores based on the strength tests performed at US Laboratories Inc. (Broomall, PA, USA). Six samples were tested for the concrete poured in August (MS and NE leg) at 2, 3, 7, and 28 days and four samples were tested for the October pour (SE leg) at 3, 4, 7, 14, and 28 days. In this work, we try to identify the spatial variation using GPR attributes.

\section{Laboratory Data Overview}
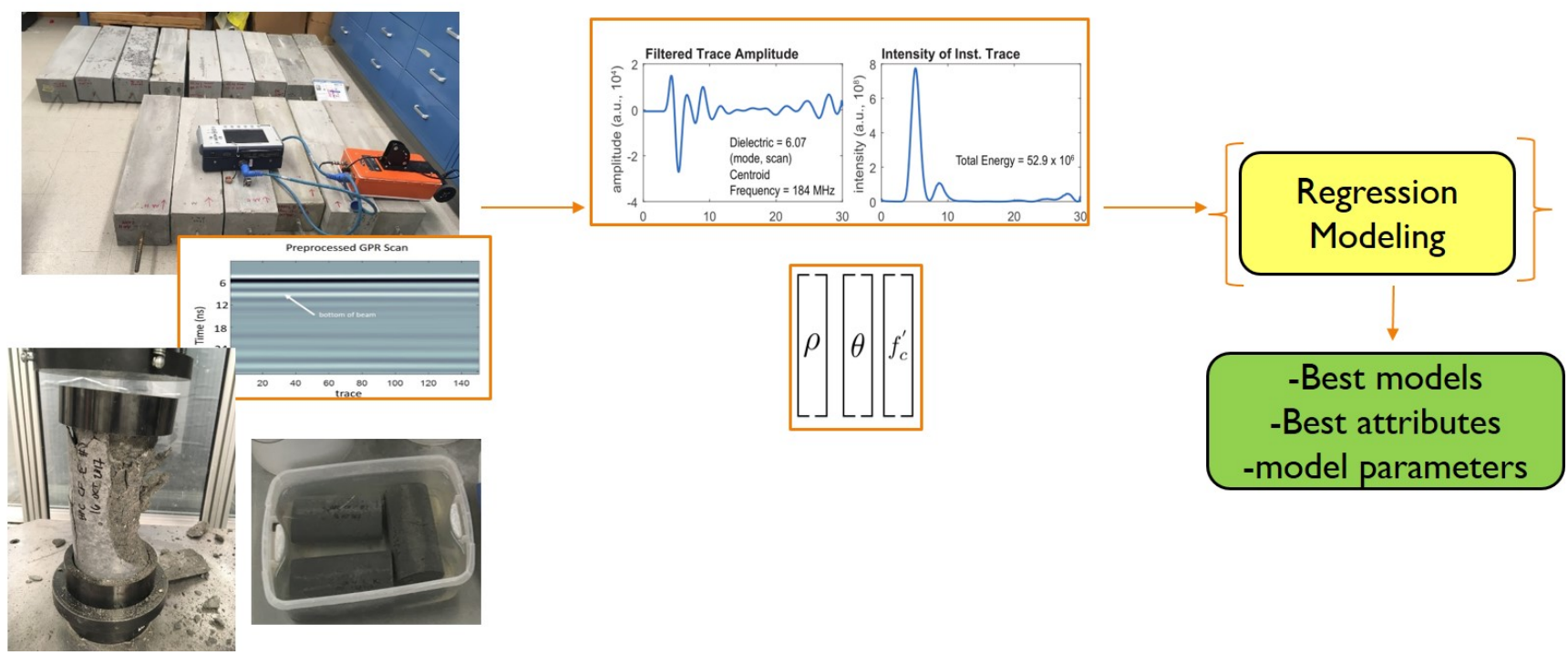

Figure 1. Overview of the experimental approach and data collected in the laboratory study. 


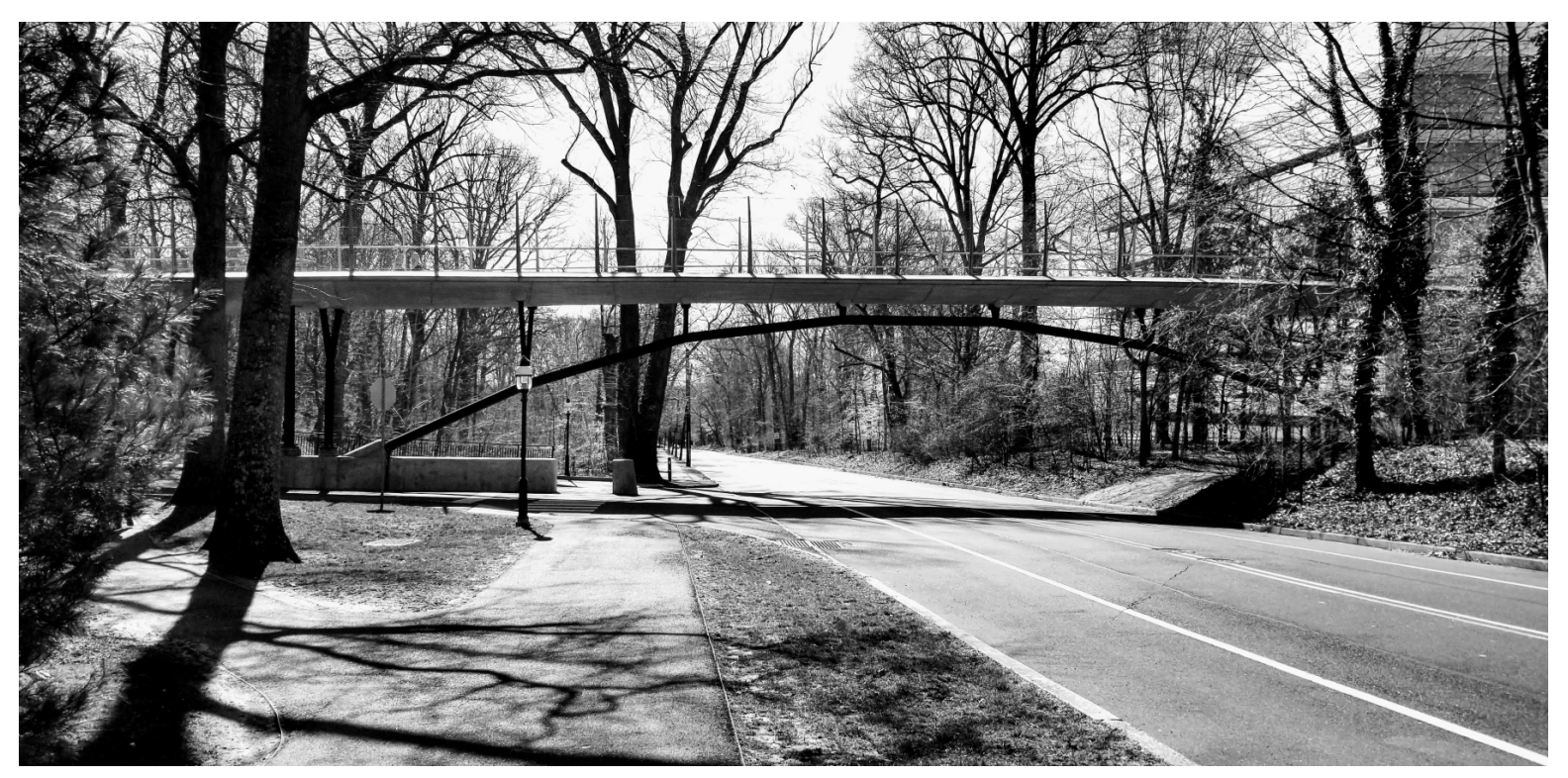

Figure 2. Front view of the Streicker bridge at Princeton University.

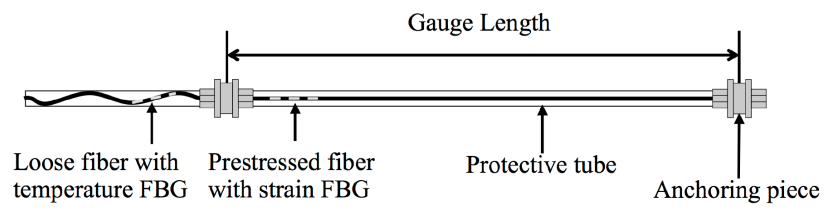

Figure 3. A single fiber-optics sensor present as part of the SHM system in the Streicker bridge (Adapted from [4]).

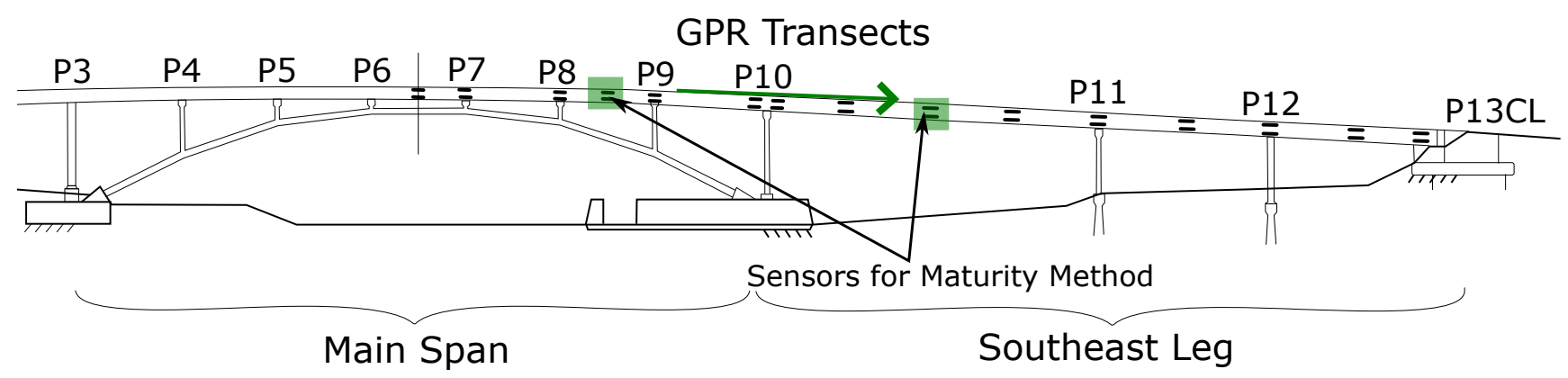

Figure 4. Elevation view of the Streicker bridge with sensor locations and direction of GPR transects.

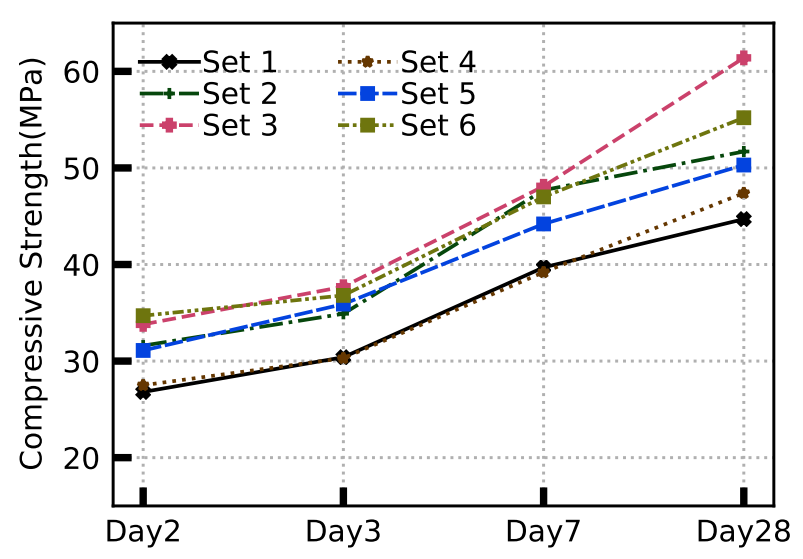

(a)

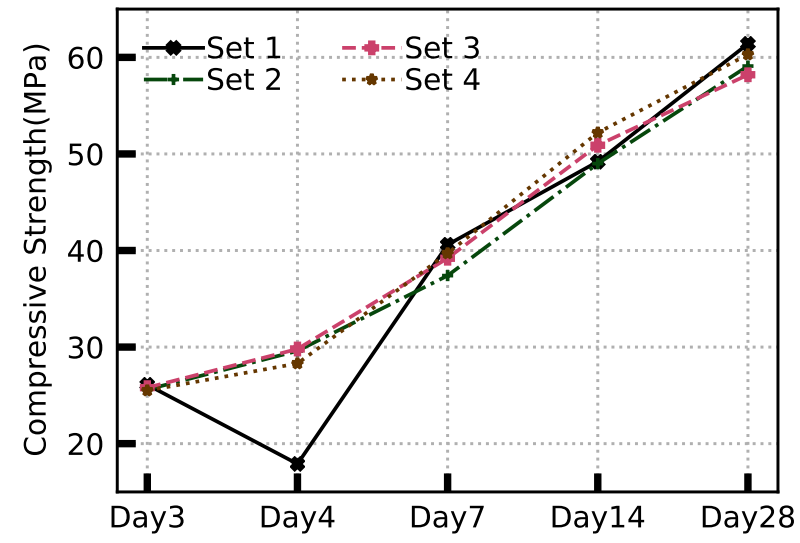

(b)

Figure 5. (a) Compressive strength for the August pours (NE and main span.) (b) Compressive strength for the October pour (SE leg). 


\subsection{GPR Survey of Streicker Bridge}

For identifying the temporal and spatial variations in concrete, the GPR data collection on Streicker bridge was performed using a $900 \mathrm{MHz}$ antenna (from GSSI) on 16 March 2020 (Note: the same antenna was used for laboratory testing and model development). Leading up to the day of the scan, the weather conditions were dry with no precipitation or surface moisture due to accumulated snow. The GPR unit is $15 \mathrm{~cm} \times 23 \mathrm{~cm} \times 18 \mathrm{~cm}$ and was rolled on the surface while being connected to a data logger (Figure 6). Longitudinal transects were collected along the northeast and southeast legs to assess the differences in the two construction phases of the concrete structure.

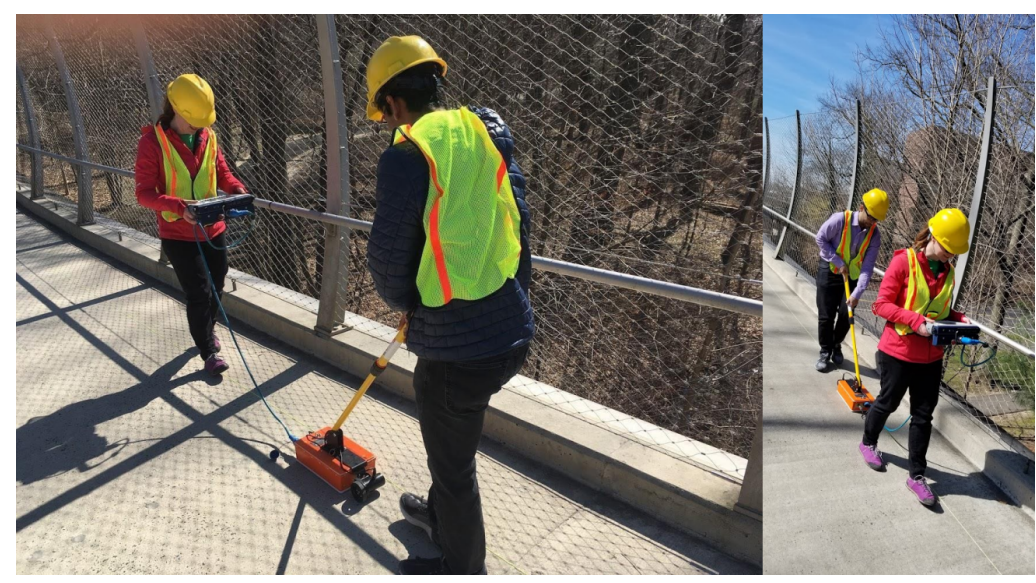

Figure 6. GPR data collection on Streicker bridge by the authors.

These longitudinal scans were collected with an average spacing of $20 \mathrm{~cm}$. The location of the transects with respect to the internal structure of the cross-section is shown in Figure 7. Only longitudinal scans were collected as the purpose of this survey was to differentiate between the legs; from SHM of the structure, no damage to the bridge was expected. The longitudinal scans were straight but their length varies due to the curved plan of the bridge. Constant lengths were obtained and used for this study as part of the data processing.

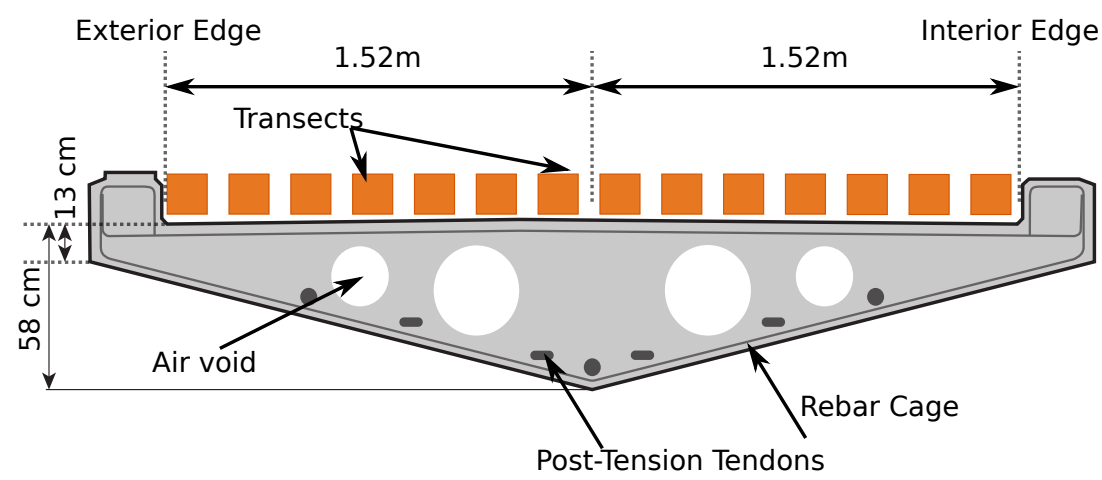

Figure 7. Southeast leg section showing location of GPR scans. Transects run longitudinally from main span down the SE and NE legs (adapted from [47]).

In addition to the $900 \mathrm{MHz}$ data described, a previous survey of the bridge from 2016 was also included for some comparisons. This survey was collected and processed in the same manner, but a $2.6 \mathrm{GHz}$ antenna was used. With this high resolution antenna, the survey focused primarily on feature detection, as described in [57].

\subsection{Data Processing}

The raw data obtained from the GPR scans were processed to calculate the primary and derived attributes. The raw amplitudes of the GPR data are highly variable with 
respect to the electromagnetic properties of the material and to antenna ground coupling, surface roughness, and other factors [58]. A standard set of basic filters were applied while preserving the relative amplitudes of the traces. The initial reflection or first break is trimmed using the STALTA algorithm, the traces are dewowed, and the scans are truncated to include only the upper $6 \mathrm{~cm}$ of the deck (Figure 8) [59-61]. Truncating the scans ensures that there are reflections from rebar present in the traces, but the spatially variable reflections at deeper depths (such as air voids, the bottom surface of the deck, and other reinforcing) are removed (Figure 8). The length of the scans are also trimmed to the same length. The trimmed and filtered traces are then converted into continuous complex traces using the Hilbert transform before attributes are computed.

(a) full B-Scan

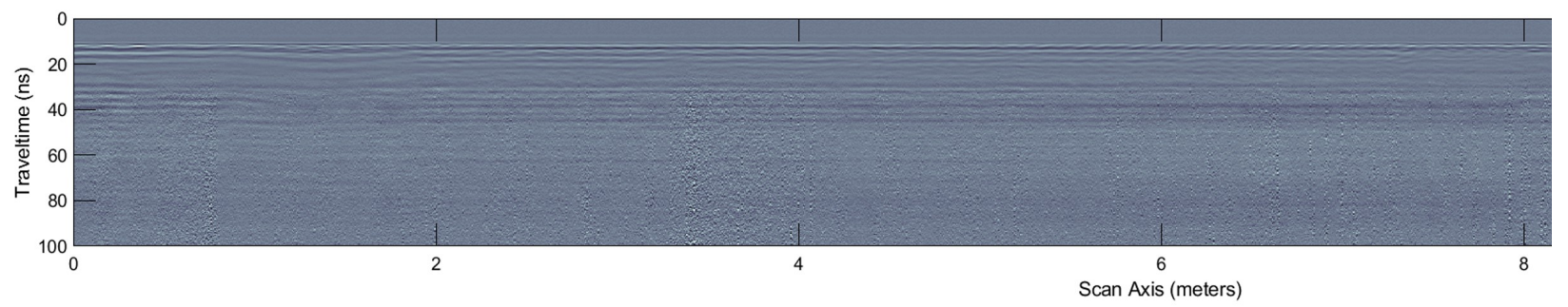

(b) preprocessed and truncated B-Scan

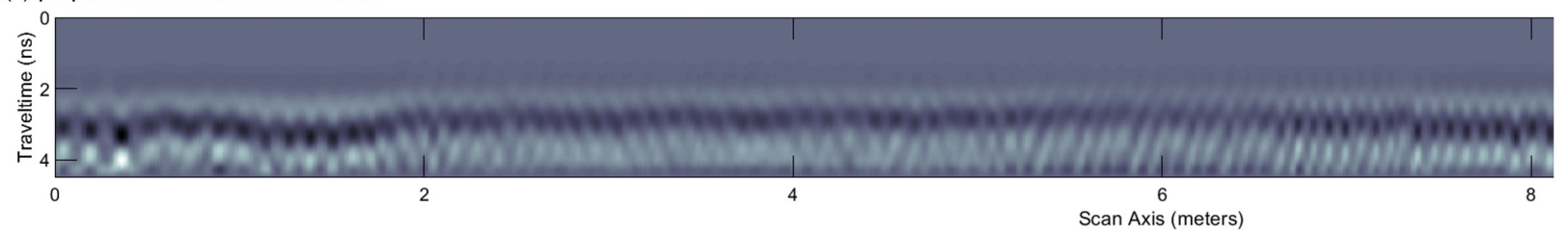

Figure 8. (a) Raw B-scan along the deck of the bridge collected with $900 \mathrm{MHz}$ antenna and (b) preprocessed B-scan truncated to remove all internal reflections except the upper rebar layer.

The attributes used in this paper for the assessment of concrete bridges are summarized in Table 1 . The attributes are calculated from the instantaneous trace that results from the Hilbert transform, which has the form $A(t)=a(t)+\phi(t) i$, where $A(t)$ is the instantaneous amplitude and $\phi$ is the phase of the signal. This selection of attributes is chosen from the best performing attributes in [54], which tested the attribute's correlation with the porosity, strength, and density of a range of lab concrete samples. Therefore, the selected attributes are expected to have correlation with the physical properties of the concrete, particularly the subtle differences between the two legs of Streicker bridge. Most of the attributes are related to the cumulative behavior of the traces and capture differences between the attenuation in different materials.

Table 1. Attribute calculation for GPR scans. The attributes are based on a Hilbert transform. Here, $c=$ speed of light, $d=$ depth of concrete, $t_{\text {top }}=$ travel time top reflection, $t_{\text {bottom }}=$ travel time bottom reflection, $\alpha_{r}=$ attenuation ratio, $\alpha_{\mathcal{c}}=$ attenuation constant, $D W=$ direct wave, $R W=$ reflected wave, $T R=$ top reflected surface.

\begin{tabular}{lclc}
\hline Main Attribute & Equation & Derived Attribute & Equation \\
\hline Instantaneous Amplitude & $A(t)$ & Total energy & $\sum A(t)^{2}$ \\
Intensity & $A(t)^{2}$ & Raw average amplitude & Average $(A)$ \\
Phase & $\phi(t)$ & Signal-to-Noise (SNR) & $\frac{P_{\text {clean }}}{P_{\text {avg }}}$ \\
Dielectric Constant $(\epsilon)$ & $\left(\frac{c\left(t_{\text {top }}-t_{\text {bottom }}\right)}{2 d}\right)^{2}$ & $\alpha_{r, D W}$ & $\frac{A_{D W}}{A_{T R}}$ \\
& & $\alpha_{r, R W}$ & $\frac{A_{T R}}{A_{R W}}$ \\
& & $\alpha_{c, D W}$ & $\frac{20}{d \log \left(\alpha_{r, D W}\right)}$ \\
& & $\alpha_{c, R W}$ & $\frac{20}{d \log \left(\alpha_{r, R W}\right)}$ \\
\hline
\end{tabular}


The data sets used for comparison with the GPR data (attributes and predicted properties) have been previously published and validated, the errors, outliers, and gaps in data are well understood. The GPR data collection and processing scheme includes a number of standard and additional steps which reduce random and measurement errors. Standard GPR data recording includes stacking, which records one compiled trace at a location that has been created from multiple recordings, thereby removing random errors and improving resolution. The data are prepared for use by the described preprocessing, including attribute calculation. The attributes used in this study represent the "average" B-scan from each leg (averaged across the width of the deck in each leg), thereby reducing the effects of any measurement errors and lateral variation in the already truncated scans. In addition to the truncation, this reduces the effect of variations from the internal structure of the bridge such as voids, tendons, and reinforcement locations that are oriented longitudinally.

\section{Modeling}

In this section, we describe the machine learning model used for quantitative prediction of compressive strength $\left(f_{c}^{\prime}\right)$, density $(\rho)$, and porosity $(\theta)$, and the maturity method used to estimate the in situ strength using the temperature measurements from the SHM system collected over the 8 year period from 2009 to 2017.

\subsection{Machine Learning Pipeline}

The laboratory samples described in Section 2 were used to train the machine learning models for prediction of compressive strength, density, and porosity using GPR scans collected from Streicker bridge. The machine learning model development process is shown in Figure 9.

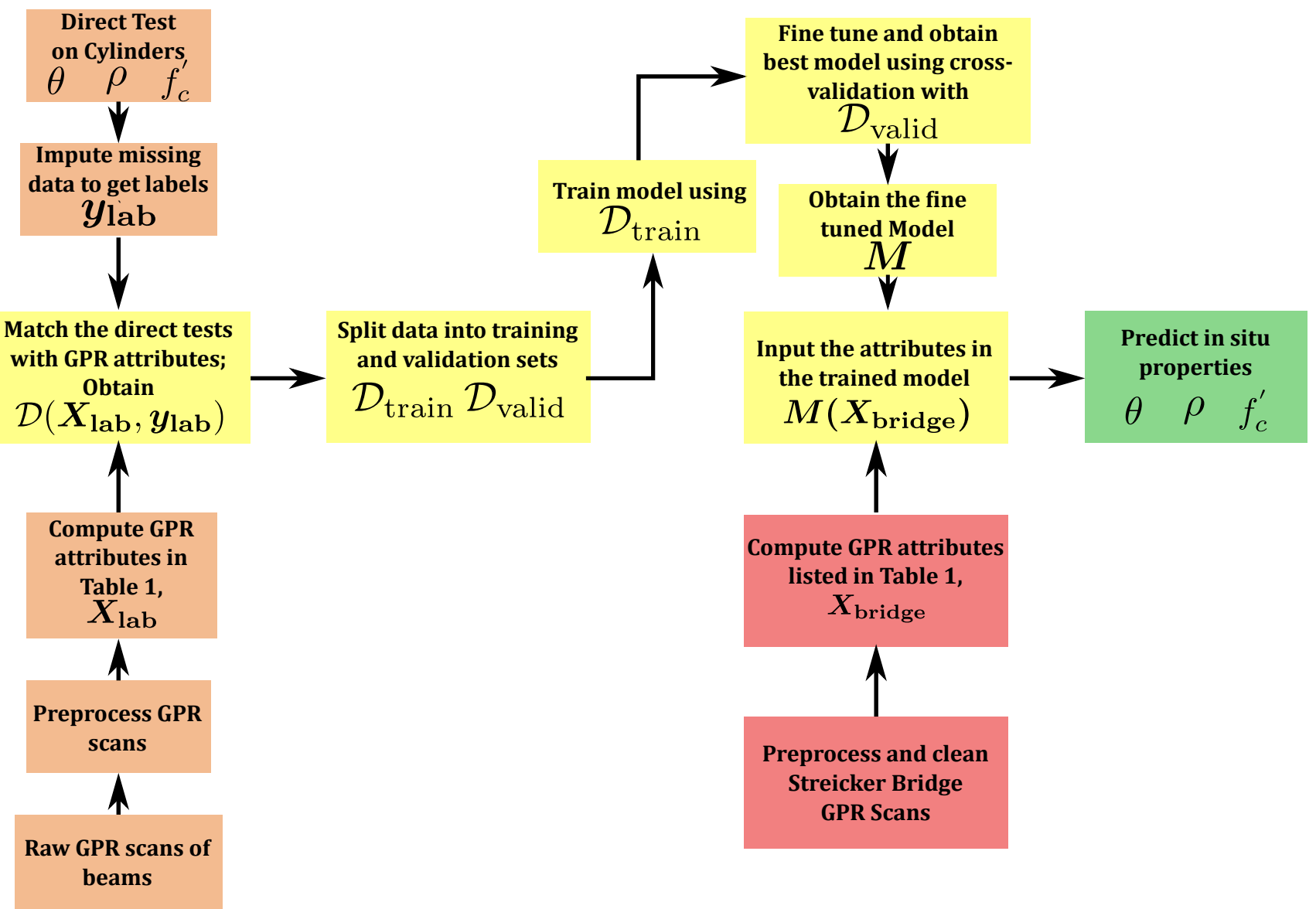

Figure 9. Flowchart depicting the steps involved in estimating the material properties using a machine learning model. 
To describe the machine learning pipeline, let the set of GPR trace attributes and their corresponding imputed labels be represented by $\mathcal{D}\left(\boldsymbol{X}_{\mathrm{lab}}, \boldsymbol{y}_{\mathrm{lab}}\right)$. Here, $\boldsymbol{X}_{\text {lab }}$ are the calculated GPR attributes which act as the "features" for the machine learning models and $\boldsymbol{y}_{\text {lab }}$ represent the imputed labels corresponding to the direct test values of material properties of the cylinders (see Figure 1). This set was separated into training and validation sets, $\mathcal{D}_{\text {train }}$ and $\mathcal{D}_{\text {validation, respectively. Using Random Forest [62] as the supervised learning }}$ model, the cross-validation [63] scores are used to determine the best performing features and fine tune the model. Random Forest was chosen as it had shown the best performance based on authors previous work [54]. These best performing attributes are then calculated from the GPR scans collected from the Streicker bridge $\left(X_{\text {bridge }}\right)$. These attributes are used for the final estimation of the material properties using the Random Forest model, $\boldsymbol{y}_{\text {bridge }}$

The key features for the current machine learning pipeline are as follows (details can be found in [54]):

1. Data imputation: The total samples tested directly in the laboratory for density, compressive strength, and porosity were 219,146 , and 73 , respectively. Since the number of samples tested for compressive strength and porosity were small, a data imputation was performed. Mean substitution was chosen as it is a standard practice in data science even if it sometimes results in statistically correlated samples [64].

2. Stratified split of train-validation data: For a small sample set such as ours, stratified splitting of training and validation sets avoids overfitting. The stratified approach further guarantees that a sample in the validation set would have the same mix of concrete in the training set while preserving the distribution of properties [63].

3. Feature selection: Since many of the attributes had more than 500 features, feature selection was adopted to improve the computational efficiency of the machine learning models. The feature selection was performed using the $f_{1}$ score. The top " $\mathrm{n}$ " features were chosen heuristically based on the $f_{1}$ scores.

4. Model tuning approach: All the machine learning models were first trained using a baseline set of hyper-parameters. These hyper-parameters were then fine-tuned to improve the predictions using randomized search and grid search [65]. The crossvalidation score was used to determine the best parameters in all these cases.

\subsection{Maturity Index Model}

The maturity method is a technique that estimates the strength of concrete from either the equivalent age (at certain temperature) or the temperature-time factor based on the reserved cores of the concrete mix [66]. The temperature-time factor (or the Nurse-Saul maturity index) is given by Equation (1)

$$
M=\sum_{0}^{t}\left(T-T_{0}\right) \Delta t
$$

where $M$ is the maturity or temperature-time factor; $t$ is time; $T$ is the average temperature during the time interval $\Delta t$; and $T_{0}$ is the datum temperature. Based on experimental studies conducted by previous researchers to develop the relationship between concrete maturity and compressive strength, a straight line best fit was found between the logarithmic value of maturity and compressive strength $[67,68]$. After combining Equation (1) with the logarithmic best fit line for the strength of the cylinders, a relationship between compressive strength $\left(f^{\prime} c\right)$ and Nurse-Saul maturity $(M)$ can be found as per Equation (2)

$$
f^{\prime} c=C_{1} \ln (M(t))+C_{2}
$$

where $C_{1}$ and $C_{2}$ are constants obtained from the cylinder test data. The compressive strength and maturity index of the cylinder tests (Figure 5) was fit to the logarithmic curve as shown in Figure 10. 


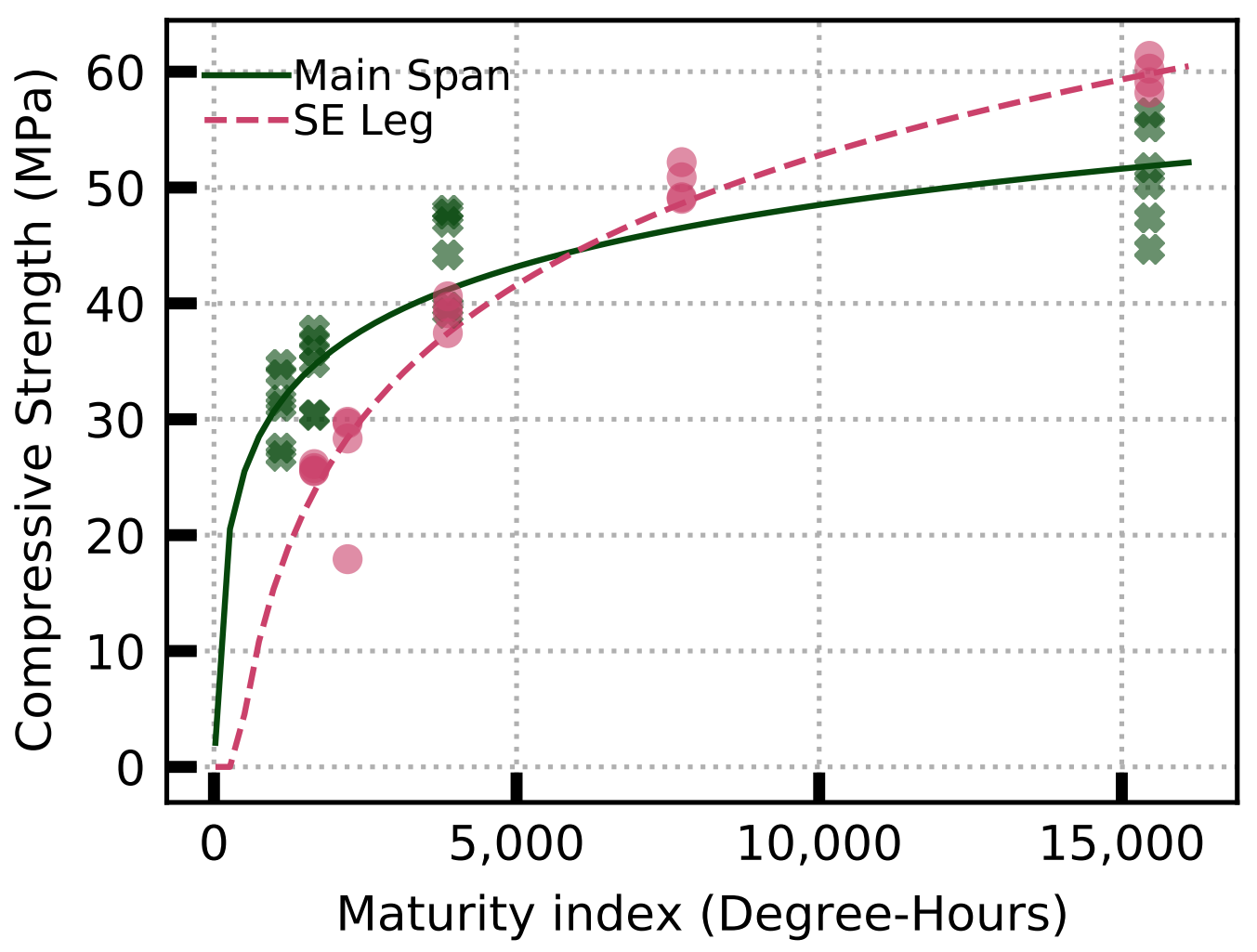

Figure 10. Compressive strength obtained as a function of maturity index based on the initial concrete core sample tests.

Based on the logarithmic fit for the cylinder data for Streicker bridge, the constants, $C_{1}$ and $C_{2}$, are obtained for the main span/northeast leg (MS/NE) and southeast leg (SE) and shown in Table 2.

Table 2. Constants of the maturity index and compressive strength logarithmic fit.

\begin{tabular}{ccc}
\hline Span & $\boldsymbol{C}_{\mathbf{1}}$ & $\boldsymbol{C}_{\mathbf{2}}$ \\
\hline Main Span & 1116.3 & -3198.7 \\
South-east Leg & 2249.7 & $-12,951.9$ \\
\hline
\end{tabular}

The temperature-time factor is calculated using the temperature data recorded by the SHM system installed in the bridge. The data used in this paper consist of the time-stamped temperature measurements from each sensor located in the main span and southeast leg through 2017.

The maturity and strength functions used in this paper take the value of temperaturetime factor to be zero for time intervals when the average concrete temperature is less than the datum temperature. As recommended by ASTM C1074-19, a datum temperature of $0{ }^{\circ} \mathrm{C}$ was used. This ensures that the analytical model does not predict loss of concrete strength when exposed to sub-zero temperature. The choice of datum temperature is important to avoid overestimation or underestimation of concrete strengths. Previous studies have shown that concrete can potentially gain strength at temperatures as low as $-10^{\circ}$ while most common values for different mixes were above freezing point, roughly $2.2{ }^{\circ} \mathrm{C}$ [68]. Estimating the actual datum temperature is not possible after construction. Since over the 8-year period only $10 \%$ had sub-zero temperature, the choice of datum is acceptable for the present work. A slight overestimation of strength is expected which would not affect the main findings. For the periods of time when the system is not active, the average temperature for the inactive period was used. The temperature-time factors for each sensor are used in the corresponding maturity-strength relationship found from the cylinder data to obtain a strength development curve for each sensor. 


\section{Results}

In this section, the results of identifying the spatial and temporal variations in concrete of the bridge are provided. First, the results from GPR scans are provided to differentiate qualitatively and quantitatively between the northeast and southeast legs of the Streicker bridge. Then, the maturity method results are presented as an upper limit for the GPR's compressive strength prediction.

\subsection{GPR Attributes: Qualitative Spatial and Temporal Variation}

In this subsection, we highlight the key attributes that identify differences between the two scanned segments, northeast and southeast, of Streicker bridge. Recall that the main span and northeast legs were constructed at the same time. First, the spatial variation between the northeast and southeast legs is demonstrated using GPR attributes collected by the authors (See Section 2) followed by the temporal variation using the attributes computed from an earlier GPR scan of the bridge.

\subsubsection{Spatial Variation}

Figure 11 shows that raw means (raw average amplitude), total energy, attenuation constant, and attenuation ratio (relative to the direct wave) are attributes which qualitatively identified the differences in the two legs. Figure 12 shows that attributes such as total phase, SNR, attenuation constant, and centroid of instantaneous frequency do not visually capture differences between the two legs.
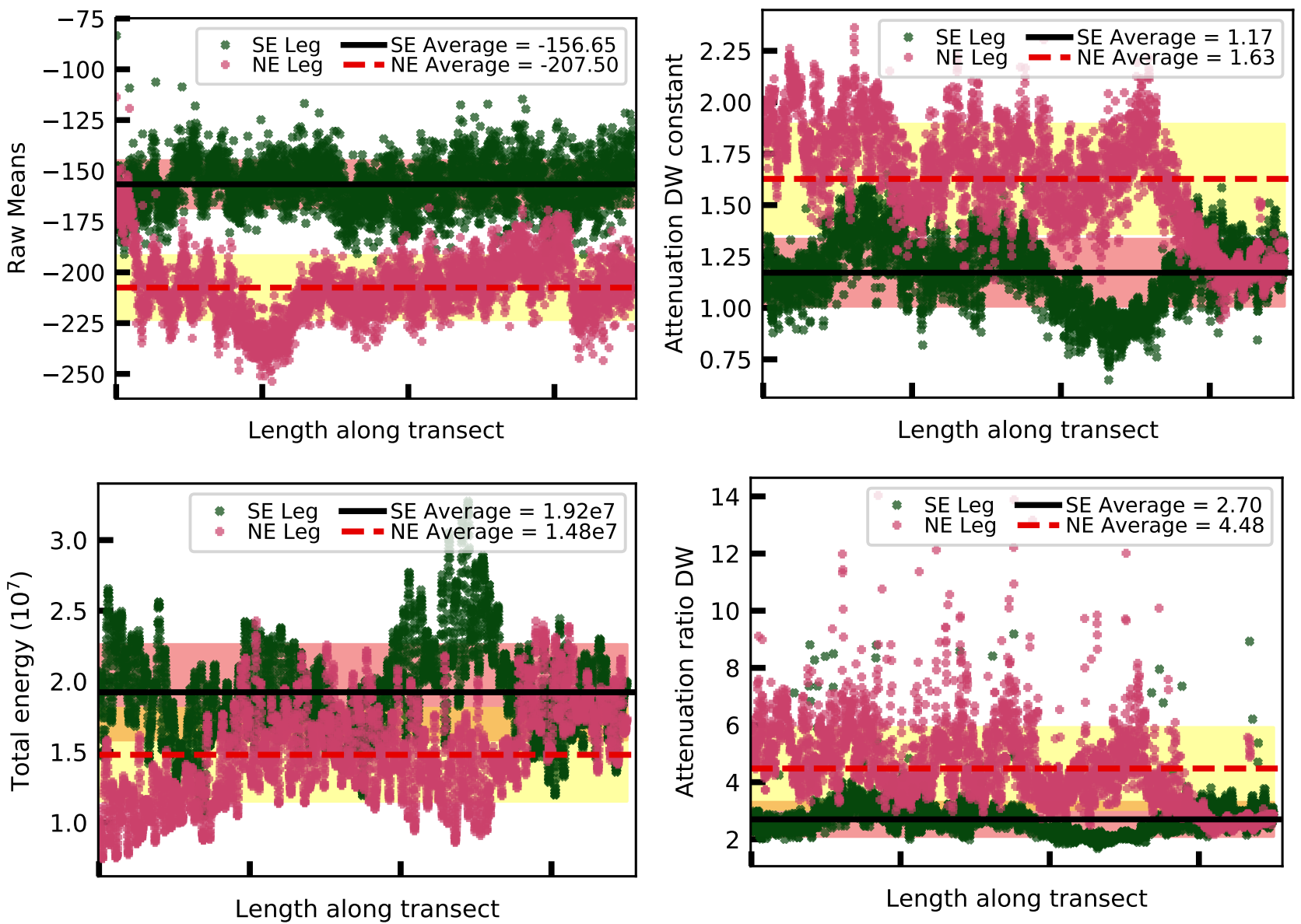

Length along transect

Figure 11. Attributes capturing qualitative differences in the two construction phases.

The red and yellow bands around the average value of attributes represent one standard deviation range. For the first set of attributes in Figure 11, there is little or no 
overlap and hence a new measurement is likely to indicate whether the concrete was from the southeast leg or the northeast leg with $85 \%$ confidence. However, for the attributes shown in Figure 12, there is considerable overlap between the 1-standard deviation bands and hence these attributes could not be used to determine which concrete phase the GPR scan is from.

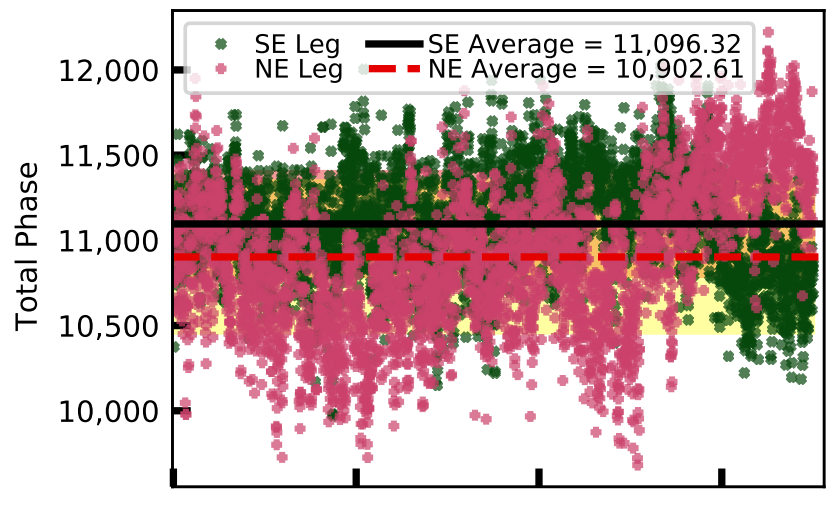

Length along transect

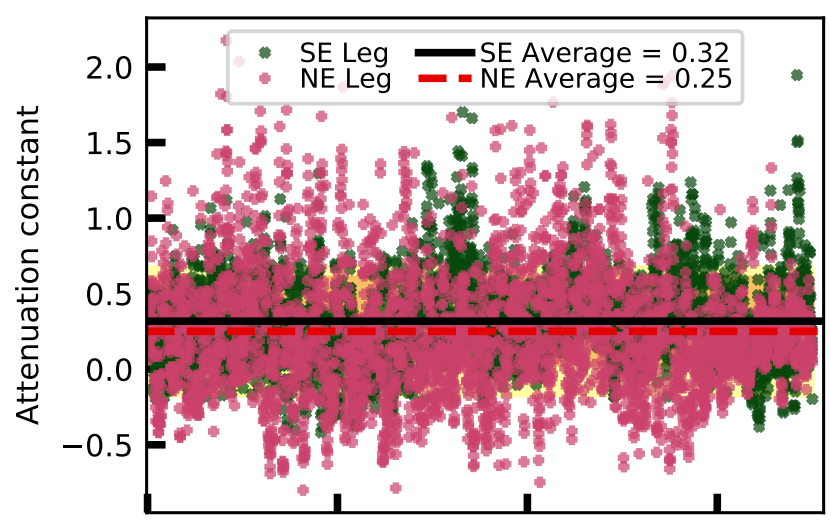

Length along transect

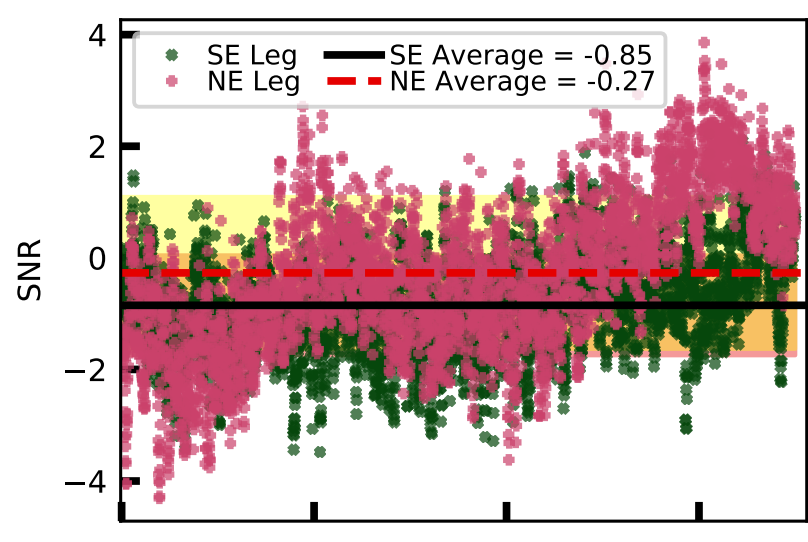

Length along transect

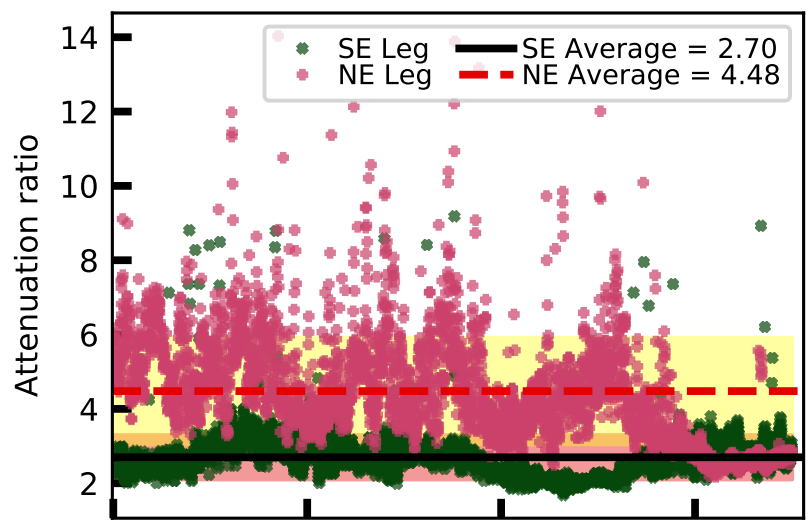

Length along transect

Figure 12. Attributes unsuccessful in capturing differences between the construction phases.

For a more quantitative comparison, the range of measured values for the two different legs are shown in Table 3.

Table 3. Range of values for various measured attributes in the southeast and northeast legs.

\begin{tabular}{ccc}
\hline Attribute & Range SE Leg & Range NE Leg \\
\hline Raw Means & {$[-542.13,196.38]$} & {$[-464.25,60.93]$} \\
Attenuation DW constant & {$[-0.73,6.16]$} & {$[-0.47,6.23]$} \\
Denergy & {$\left[5.64 \times 10^{5}, 1.11 \times 10^{8}\right]$} & {$\left[1.8 \times 10^{5}, 9.37 \times 10^{7}\right]$} \\
Attenuation DW ratio & {$[0.58,101.32]$} & {$[0.70,107.22]$} \\
Total Phase & {$\left[0.58 \times 10^{4}, 1.70 \times 10^{4}\right]$} & {$\left[0.48 \times 10^{4}, 1.65 \times 10^{4}\right]$} \\
SNR & {$[-16.797,12.224]$} & {$[-16.899,14.009]$} \\
Attenuation constant & {$[-6.51,15.00]$} & {$[-6.18,20.17]$} \\
Dielectric constant & {$[3.01,78.74]$} & {$[3.10,93.71]$} \\
\hline
\end{tabular}

Two key statistical measures used for determining whether the means of two different test samples can be considered different are Welch's $t$-test and Mann-Whitney U-Test [69]. These tests are used to further characterize the spatial variation in concrete. Welch's $t$-test tests the hypothesis that two populations have the same mean. A low $p$-value in the test indicates that the means are different. The test is most commonly employed to differentiate 
samples which have many overlapping values. Mann-Whitney U-test determines whether the two samples themselves are independent, with low scores indicating stronger independence. The results are shown in Table 4 . The absolute value of the scores are useful for relative comparison. Hence, based on the combination of results from the two tests, it can be inferred that the mean values of GPR scan attributes for the two legs are different and that they are obtained from different populations.

Table 4. Statistical comparison (with $p$-values) of the attributes for the northeast and southeast legs.

\begin{tabular}{lcccc}
\hline Attribute & Welch's t-Score & $p$-Value & Mann-Whitney U-Score & $p$-Value \\
\hline Raw Means & 154.52 & 0.0 & $12.41 \times 10^{6}$ & 0.0 \\
Attenuation DW constant & 86.57 & 0.0 & $1.03 \times 10^{6}$ & 0.0 \\
Denergy & 55.60 & 0.0 & $1.01 \times 10^{7}$ & 0.0 \\
Attenuation DW ratio & -67.88 & 0.0 & $1.20 \times 10^{6}$ & 0.0 \\
Total Phase & 21.19 & $1.11 \times 10^{-96}$ & $4.88 \times 10^{6}$ & $1.14 \times 10^{-95}$ \\
SNR & 21.06 & $1.48 \times 10^{-95}$ & $7.06 \times 10^{6}$ & $1.12 \times 10^{-80}$ \\
Attenuation constant & 7.73 & $1.26 \times 10^{-14}$ & $4.54 \times 10^{6}$ & $1.96 \times 10^{-28}$ \\
Dielectric constant & -22.41 & $1.62 \times 10^{-107}$ & $5.50 \times 10^{6}$ & $3.6 \times 10^{-79}$ \\
Attenuation ratio & -11.42 & $6.38 \times 10^{-30}$ & $7.58 \times 10^{-14}$ \\
\hline
\end{tabular}

The low $p$-value of both the Welch's t-score and Mann-Whitney U-score as shown in Table 4 indicates that (i) the mean values of both the legs are different in a statistically significant way and (ii) the samples themselves are taken from different populations. Those are independent and interesting findings in their own regard which indicate the value in qualitative attribute based comparisons of GPR attributes in concrete inspections. These statistical measures confirm the capability of GPR attributes to qualitatively distinguish between different concrete mixes used in the same structure.

\subsubsection{Temporal Variation}

To identify the temporal variation in concrete, the above attributes from the $900 \mathrm{MHz}$ antenna (2020) are compared with GPR data collected in Nov, 2016 with a $2.6 \mathrm{GHz}$ antenna for a previous study more focused on high resolution feature mapping [47]. A special deicing agent is used on the bridge to avoid corroding the exposed rebar on the surface, so seasonal accumulation of chlorides over the winter should be negligible in the November 2016 to March 2020 comparison. The temperature, humidity, and very low precipitation [70] for the week preceding GPR measurements in both surveys were similar, so the effect of moisture related seasonal changes in the dielectric properties and other attributes are minimal. The results are presented in Table 5. Since two different antennas were used in 2016 and 2020 (2.6 GHz vs. $900 \mathrm{MHz}$ ), attributes that consider amplitude values directly, such as raw means and total energy were normalized for 2016 to match 2020 values and minimize the effect of using two different antennas. Recall that the $900 \mathrm{MHz}$ antenna used primarily in this work matches the laboratory data and predictive modeling; the $2.6 \mathrm{GHz}$ antenna was not available and not used in 2020.

Table 5. Comparison of attribute values for southeast and northeast legs between 2016 and 2020 measurements. Note, * represents normalized value to account for different antennas.

\begin{tabular}{lcccccc}
\hline \multirow{2}{*}{ Attribute } & \multicolumn{2}{c}{ Southeast Leg } & \multicolumn{2}{c}{ Northeast Leg } & \multicolumn{2}{c}{ Ratio SE/NE } \\
& $\mathbf{2 0 1 6}$ & $\mathbf{2 0 2 0}$ & $\mathbf{2 0 1 6}$ & $\mathbf{2 0 2 0}$ & $\mathbf{2 0 1 6}$ & $\mathbf{2 0 2 0}$ \\
\hline Raw Means & $-160.4^{*}$ & -156.65 & $-169.5^{*}$ & -207.50 & 0.95 & 0.75 \\
Attenuation constant (DW) & -0.60 & 1.17 & -1.29 & 1.63 & 0.46 & 0.72 \\
Total energy & $3.49 \times 10^{*} *$ & $1.92 \times 10^{7}$ & $3.50 \times 10^{7} *$ & $1.48 \times 10^{7}$ & 1.0 & 1.30 \\
Attenuation ratio (DW) & 3.41 & 2.70 & 1.84 & 4.48 & 1.85 & 0.60 \\
Total Phase & $0.419 \times 10^{4}$ & $1.11 \times 10^{4}$ & $0.450 \times 10^{4}$ & $1.09 \times 10^{4}$ & 0.93 & 1.01 \\
Attenuation constant & -1.07 & 0.32 & -0.36 & 0.25 & 2.97 & 1.28 \\
Attenuation ratio & 21.72 & 3.19 & 25.64 & 5.39 & 0.85 & 0.59 \\
\hline
\end{tabular}


The qualitative comparison of the attributes over a gap of 4 years using two antennas provides some interesting insights. The ratio of attribute values for the two legs increased for attenuation constant (with respect to direct wave), total energy, and total phase, while the ratio decreased for raw means, attenuation ratio (with respect to both the direct wave and the reflected wave), and attenuation constant (with respect to reflected wave). These could be explained by a higher loss in concrete cover in the southeast leg compared to the northeast leg due to higher pedestrian and golf cart traffic. As the concrete cover decreases, the reflected signals have thinner concrete medium to travel before they penetrate into the voids resulting in proportionally lower travel time in the concrete than the second medium (grout, air, etc.). As a result of the change in the medium, the computed attributes could have higher negative values. This is reflected in the higher negative raw means value and the decrease in the ratio over the 4 years period. However, an increase in negative values of the attribute would still result in higher total energy as the the total energy only takes the square of the values into account. For a reduced cover, the values of $\alpha_{D W}$ decrease while the $\alpha_{T R}$ remains constant (see Table 1) which would explain the change over time in attributes such as attenuation constant and ratio. The total phase comparison does not change significantly over time, as it is largely determined by the antenna frequency characteristics and therefore should not change significantly between legs. This increased loss of concrete cover can be seen in Figure 13. The aggregates are visible on the southeast leg while it is not the case with the northeast leg.

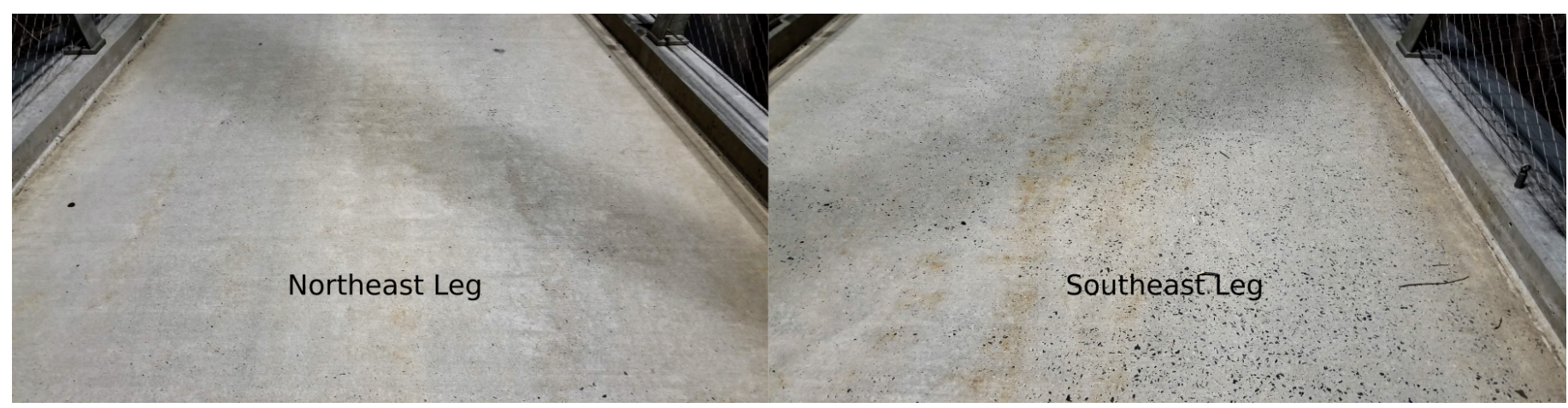

Figure 13. Figure showing increased loss of cover on the southeast leg compared to northeast leg.

\subsection{Quantitative Differences between Legs}

In this section, quantitative analyses of the GPR attributes of the northeast and southeast legs are presented to identify the spatial differences. The quantitative analysis is based on the machine learning framework and maturity method described in Section 3.

\subsubsection{In Situ Property Estimation Using GPR Attributes}

Different material properties required different attributes for the best prediction. The most successful attributes were instantaneous amplitude for porosity and compressive strength, while it was intensity for the density prediction. Using these GPR attributes and fine tuned Random Forest models from [54], the compressive strength, density, and porosity were predicted using all the GPR transects collected. These predicted values and the average for each leg is shown in Figure 14 (Note: outlier datum points were removed).

Figure 14 shows the predicted values for each of these properties are fairly scattered. This is attributed to the macro-scale variation along the length of the scans from the irregular presence of plastic tubes (voids in Figure 7) and reinforcing along each transect. Hence, in the discussion of the results, we only focus on the average values of these material properties over all the transects. Though not an accurate representation, it is in line with the practice of using a single number to quantify material properties for civil engineering structures. 

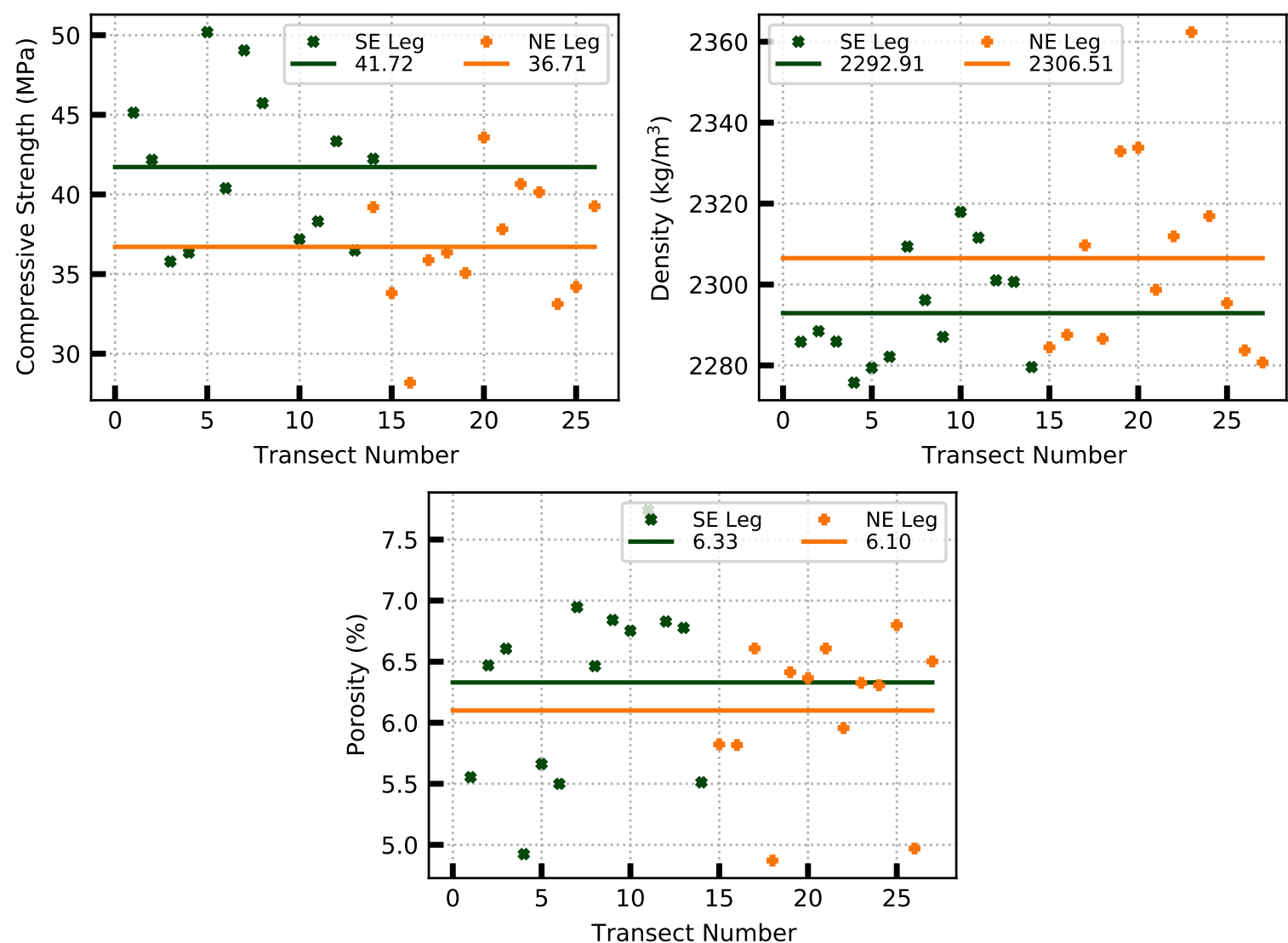

Figure 14. Spatial differences in material properties between the southeast and northeast legs.

The compressive strength predicted by the machine learning model is less than the measured compressive strength from the reserve cores. The compressive strength is not actually expected to have reduced over time (it is expected to have increased) and the lower predicted values are a result of using small training sets of lab data to create the models. The predicted values still identify a $12 \%$ difference between the two legs, while the initial difference between the reserved cores was $13.6 \%$. This shows the potential of using GPR attributes to identify relative difference over space.

The density predicted by the machine learning model is close to those expected in reallife settings for this type of concrete. The predicted density is $\approx 2300 \mathrm{~kg} / \mathrm{m}^{3}$ for both legs while the concrete mix used for the construction of the bridge had a density of $2400 \mathrm{~kg} / \mathrm{m}^{3}$. It is a $4 \%$ lower prediction than the expected value but it is acceptable. This variation could be attributed to embedded air voids in the structure lowering the effective density compared to the training set based on laboratory fabricated samples with only one piece of reinforcing steel embedded.

Finally, the predicted porosity values for both the legs are around $6 \%$. This porosity includes the connected pores and not include dead-end pores and unconnected air voids. Saturated pores would not be included in this porosity. Although there is no direct way to verify the porosity values, it is possible to compare them with those found in literature. The in situ porosity values reported for concrete structures is between 5 and $10 \%$. The reported value falls comfortably in this range. The relative values do not follow the expected trend of higher porosity-lower strength, though this could be due to other factors in the mix design, such as the high rate of strength development required in the SE leg.

\subsubsection{Compressive Strength Calculation Using Maturity Method}

Based on the Equation (2) and the constants obtained using the reserved concrete cores (Table 2), the mean 8-year compressive strength for all sensors in main span is $57.12 \mathrm{MPa}$ and 74.8 MPa in the southeast leg (see Figure 15). The higher compressive strength of 
the southeast leg compared to the main-span is attributed to the higher initial strength of the concrete mix and rapid early strength gain of that particular concrete mix. Hence, the method predicts a gain of $6.2 \mathrm{MPa}$ for main span and $15.1 \mathrm{MPa}$ for the southeast leg for the same period of 8-years. These estimates should be considered as upper bounds on the compressive strengths as the maturity method overestimates the strength at later stages. This results from the logarithmic function used to predict the strength gain for the entire life of the concrete. The issue is aggravated when the method is applied to concrete mixes designed for early strength gain [68]. For strength development at specific sensor locations, readers can refer to [71].

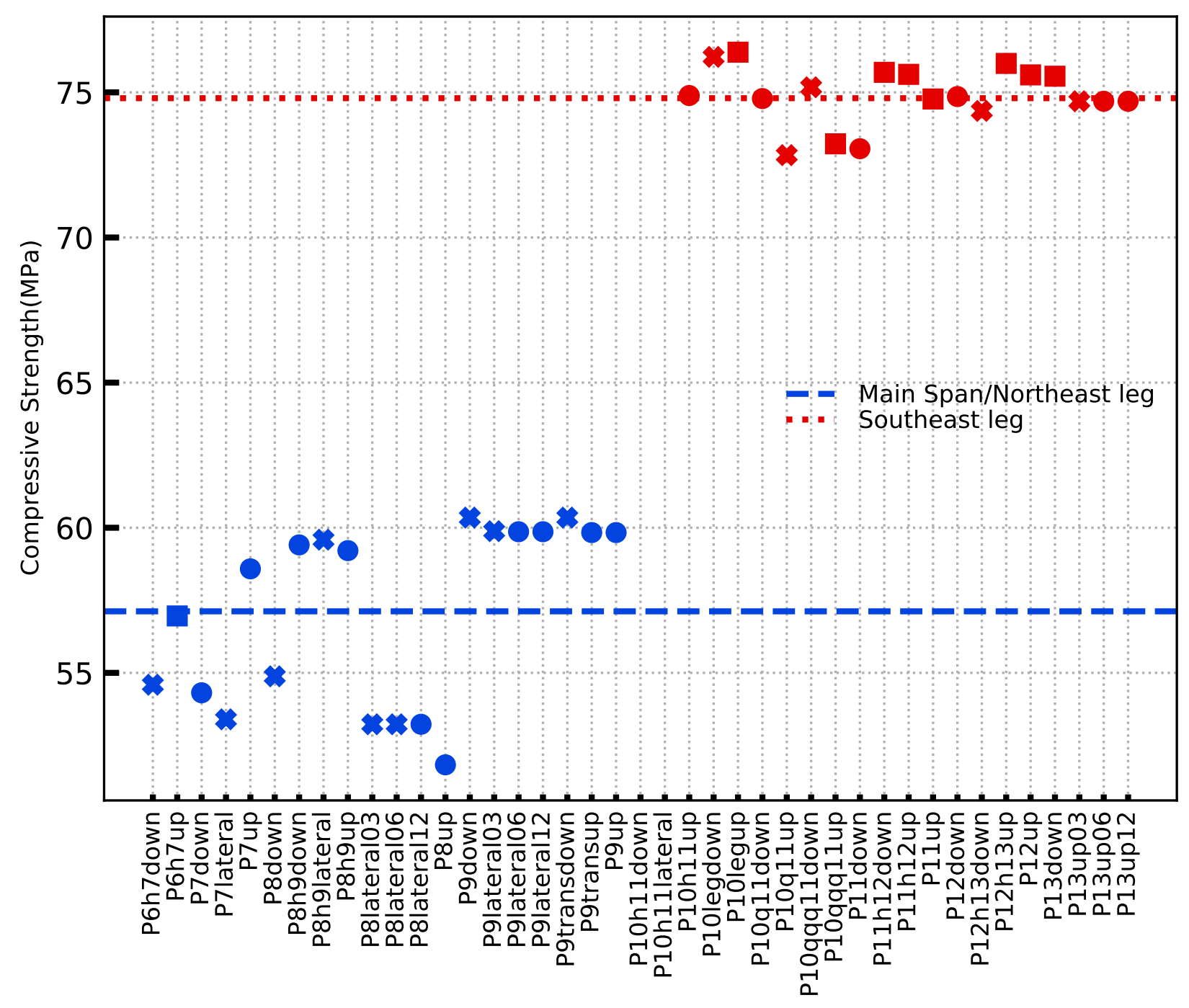

Sensor Location

Figure 15. Strength calculation at different sensor locations using maturity method.

\section{Conclusions and Discussion}

In this paper, GPR attributes were used to estimate temporal and spatial variation of in situ material properties of mature concrete. Variation in in situ material properties was evaluated on a concrete pedestrian bridge at Princeton University campus using GPR attributes. The novelty of the present work is three-fold: (1) GPR attributes are used to qualitatively differentiate between different mixes of concrete in place, (2) machine learning algorithms are developed for quantitative differentiation, and (3) maturity index is demonstrated as a method for establishing bounds on the predictions of mature concrete strength. The conclusions are summarized below: 
1. Instantaneous amplitude and summary attributes can statistically distinguish between the concrete in Streicker bridge on the basis of relative material properties.

2. Spatial variation in the physical properties of the two phases of concrete is identified with amplitude-based attributes such as raw means, total energy, and two different measures of attenuation.

3. Temporal variation in the physical properties over a four-year period is difficult to determine due to the use of different antennas and seasonal differences, but the comparison does identify how sensitive attributes are to the antenna relative to the different concrete.

4. The GPR attributes predict a 5.01 MPa difference in the mean compressive strength, a $13.6 \mathrm{~kg} / \mathrm{m}^{3}$ difference in density, and a $0.23 \%$ difference in porosity between the southeast and northeast legs of the bridge.

5. The quantitative strength predictions from the GPR attributes are reasonable and fall between the lower bound of the 28-day reserved concrete core strength and the upper bound from the maturity method and temperature history of the concrete.

The quantitative estimates for density and porosity cannot be verified through alternative measurements but the values are within reasonable ranges for the concrete mix used in Streicker bridge. While the current work is limited due to the availability of samples to train models on, the availability of temperature and GPR data from the bridge enable a range of techniques to be applied. For GPR attributes to become an accepted industry practice for establishing spatial variability in properties like rebound hammer technique, further research into the development of calibration charts for attribute values and material properties are required. In future works, these studies would be carried out to identify point, local, global relationships between material properties and GPR and more fully describe the effects of data collection settings like antenna frequency, seasonal variability, and variability in internal reflectors. Some immediate directions towards these would be a one-on-one comparison between traces with consistent profiles to understand and calibrate the GPR attributes with concrete properties. Long term projects using total phase could present a solution to evaluate material property evolution as these attributes are only dependent on frequency of the internal reflected waves and not affected by concrete cover. Finally, other NDT techniques like rebound hammer or ultrasonic testing could be conducted to provide additional data about spatial and material variability. The present work paves the way for future research in expanding the use of GPR attributes for assessments and laying the groundwork for developing codes of practice for using GPR for maintenance of transport infrastructure.

Author Contributions: Conceptualization, V.K., I.M.M., B.G.; methodology, I.M.M., V.K.; software, V.K.; validation, I.M.M.,V.K.; formal analysis, V.K., I.M.M., S.A.L.; data curation, I.M.M.; writingoriginal draft preparation, V.K.; writing-review and editing, I.M.M.; visualization V.K., I.M.M., S.A.L.; supervision, I.M.M., B.G.; funding acquisition, I.M.M., B.G. All authors have read and agreed to the published version of the manuscript.

Funding: I.M.M. was supported by NSF GRFP \#1148900 and S.A.L. was supported by the NM AMP Program (NSF HRD-1305011).

Institutional Review Board Statement: Not Applicable.

Informed Consent Statement: Not Applicable.

Data Availability Statement: The data supporting the current study can be provided at a reasonable request to the corresponding author.

Acknowledgments: The authors would like to acknowledge and thank Joseph Vocaturo for the help in preparation of laboratory samples; the past and present members of SHMlab for maintaining the SHM system on Streicker Bridge; Mauricio Periera for GPR scan collection on Streicker Bridge. 
Conflicts of Interest: The authors declare no conflict of interest. The funders had no role in the design of the study; in the collection, analyses, or interpretation of data; in the writing of the manuscript, or in the decision to publish the results.

\section{References}

1. Betti, R. Aging Infrastructure: Issues, Research, and Technology. Buildings and Infrastructure Protection Series. Infrastructure Protection and Disaster Management Division; Science \& Technology Directorate, US Department of Homeland Security: Wahsington, DC, USA, 2010.

2. ASCE. 2021 Infrastructure Report Card; ASCE: Reston, VA, USA, 2021.

3. ASCE. Failure to Act: Economic Impacts of Status Quo Investment Across Infrastructure Systems; Technical Report; ASCE: Reston, VA, USA, 2021. Available online: https://www.asce.org/failuretoact/ (accessed on 2 February 2021).

4. Glisic, B.; Inaudi, D. Fibre Optic Methods for Structural Health Monitoring; John Wiley \& Sons: Hoboken, NJ, USA, 2008.

5. Scott, M.; Rezaizadeh, A.; Delahaza, A.; Santos, C.; Moore, M.; Graybeal, B.; Washer, G. A comparison of nondestructive evaluation methods for bridge deck assessment. NDT E Int. 2003, 36, 245-255. [CrossRef]

6. Rehman, S.K.U.; Ibrahim, Z.; Memon, S.A.; Jameel, M. Nondestructive test methods for concrete bridges: A review. Constr. Build. Mater. 2016, 107, 58-86. [CrossRef]

7. Alani, A.M.; Aboutalebi, M.; Kilic, G. Applications of ground penetrating radar (GPR) in bridge deck monitoring and assessment. J. Appl. Geophys. 2013, 97, 45-54. [CrossRef]

8. An, Y.; Chatzi, E.; Sim, S.H.; Laflamme, S.; Blachowski, B.; Ou, J. Recent progress and future trends on damage identification methods for bridge structures. Struct. Control. Health Monit. 2019, 26, e2416. [CrossRef]

9. Chen, Z.; Zhou, X.; Wang, X.; Dong, L.; Qian, Y. Deployment of a smart structural health monitoring system for long-span arch bridges: A review and a case study. Sensors 2017, 17, 2151. [CrossRef] [PubMed]

10. Ko, J.; Ni, Y.Q. Technology developments in structural health monitoring of large-scale bridges. Eng. Struct. 2005, 27, 1715-1725 [CrossRef]

11. Cao, W.; Liu, W.; Koh, C.G.; Smith, I.F. Exploring potential benefits of bridge condition assessment in highway operations. In Proceedings of the IABSE Congress 2019, New York, NY, USA, 4-6 September 2019; IABSE: Zurich, Switzerland, 2019.

12. Fu, G.; Devaraj, D. Bridge Management Using Pontis and Improved Concepts. In Bridge Engineering Handbook, 2nd ed.; CRC Press: Boca Raton, FL, USA, 2014; pp. 233-246.

13. Kim, J.; Ahn, Y.; Yeo, H. A comparative study of time-based maintenance and condition-based maintenance for optimal choice of maintenance policy. Struct. Infrastruct. Eng. 2016, 12, 1525-1536. [CrossRef]

14. Ni, Y.; Wong, K. Integrating bridge structural health monitoring and condition-based maintenance management. In Proceedings of the 4th International Workshop on Civil Structural Health Monitoring, Berlin, Germany, 6-8 November 2012; pp. 6-8.

15. Rens, K.L.; Wipf, T.J.; Klaiber, F.W. Review of nondestructive evaluation techniques of civil infrastructure. J. Perform. Constr. Facil. 1997, 11, 152-160. [CrossRef]

16. Giannini, R.; Sguerri, L.; Paolacci, F.; Alessandri, S. Assessment of concrete strength combining direct and NDT measures via Bayesian inference. Eng. Struct. 2014, 64, 68-77. [CrossRef]

17. Li, Z.; Li, F.; Zdunek, A.; Landis, E.; Shah, S.P. Application of acoustic emission technique to detection of rebar corrosion in concrete. Mater. J. 1998, 95, 68-81.

18. Rhazi, J.; Kharrat, Y.; Ballivy, G.; Rivest, M. Application of acoustical imaging to the evaluation of concrete in operating structures Spec. Publ. 1997, 168, 221-232.

19. Holford, K.M.; Davies, A.; Pullin, R.; Carter, D. Damage location in steel bridges by acoustic emission. J. Intell. Mater. Syst. Struct. 2001, 12, 567-576. [CrossRef]

20. Maser, K.R.; Roddis, W.K. Principles of thermography and radar for bridge deck assessment. J. Transp. Eng. 1990, $116,583-601$. [CrossRef]

21. Clark, M.; McCann, D.; Forde, M. Application of infrared thermography to the non-destructive testing of concrete and masonry bridges. NDT E Int. 2003, 36, 265-275. [CrossRef]

22. Chang, Y.F.; Wang, C.Y. A 3-D image detection method of a surface opening crack in concrete using ultrasonic transducer arrays. J. Nondestruct. Eval. 1997, 16, 193-203. [CrossRef]

23. Mohamed, O.A.; Rens, K.L. Ultrasonic testing of properties of 50 year old concrete. Mater. Eval. 2001, 59, 1426-1430.

24. Shiotani, T.; Aggelis, D.G.; Makishima, O. Global monitoring of large concrete structures using acoustic emission and ultrasonic techniques: Case study. J. Bridge Eng. 2009, 14, 188-192. [CrossRef]

25. Rens, K.L.; Greimann, L.F. Ultrasonic approach for nondestructive testing of civil infrastructure. J. Perform. Constr. Facil. 1997, 11, 97-104. [CrossRef]

26. Davis, A.; Ansari, F.; Gaynor, R.; Lozen, K.; Rowe, T.; Caratin, H.; Heidbrink, F.; Malhotra, V.; Simons, B.; Carino, N. Nondestructive Test Methods for Evaluation of Concrete in Structures; American Concrete Institute, ACI: Farmington Hills, MI, USA, 1998; Volume 228.

27. Ervin, B.L.; Kuchma, D.A.; Bernhard, J.T.; Reis, H. Monitoring corrosion of rebar embedded in mortar using high-frequency guided ultrasonic waves. J. Eng. Mech. 2009, 135, 9-19. [CrossRef] 
28. Azari, H.; Nazarian, S.; Yuan, D. Assessing sensitivity of impact echo and ultrasonic surface waves methods for nondestructive evaluation of concrete structures. Constr. Build. Mater. 2014, 71, 384-391. [CrossRef]

29. Krause, M.; Milmann, B.; Mielentz, F.; Streicher, D.; Redmer, B.; Mayer, K.; Langenberg, K.J.; Schickert, M. Ultrasonic imaging methods for investigation of post-tensioned concrete structures: A study of interfaces at artificial grouting faults and its verification. J. Nondestruct. Eval. 2008, 27, 67-82. [CrossRef]

30. Hsieh, K.H.; Halling, M.W.; Barr, P.J. Overview of vibrational structural health monitoring with representative case studies. J. Bridge Eng. 2006, 11, 707-715. [CrossRef]

31. Samman, M.M.; Biswas, M. Vibration testing for nondestructive evaluation of bridges. I: Theory. J. Struct. Eng. 1994, 120, 269-289. [CrossRef]

32. Kazemi, M.; Madandoust, R.; de Brito, J. Compressive strength assessment of recycled aggregate concrete using Schmidt rebound hammer and core testing. Constr. Build. Mater. 2019, 224, 630-638. [CrossRef]

33. Breccolotti, M.; Bonfigli, M.F.; Materazzi, A.L. Influence of carbonation depth on concrete strength evaluation carried out using the SonReb method. NDT E Int. 2013, 59, 96-104. [CrossRef]

34. Cristofaro, M.; Viti, S.; Tanganelli, M. New predictive models to evaluate concrete compressive strength using the SonReb method. J. Build. Eng. 2020, 27, 100962. [CrossRef]

35. Diamanti, N.; Annan, A.P.; Redman, J.D. Concrete bridge deck deterioration assessment using ground penetrating radar (GPR). J. Environ. Eng. Geophys. 2017, 22, 121-132. [CrossRef]

36. Chen, D.H.; Wimsatt, A. Inspection and condition assessment using ground penetrating radar. J. Geotech. Geoenviron. Eng. 2010, 136, 207-214. [CrossRef]

37. Maser, K.R. Condition assessment of transportation infrastructure using ground-penetrating radar. J. Infrastruct. Syst. 1996, 2, 94-101. [CrossRef]

38. Barnes, C.L.; Trottier, J.F. Ground-penetrating radar for network-level concrete deck repair management. J. Transp. Eng. 2000, 126, 257-262. [CrossRef]

39. Sbartaï, Z.; Laurens, S.; Viriyametanont, K.; Balayssac, J.; Arliguie, G. Non-destructive evaluation of concrete physical condition using radar and artificial neural networks. Constr. Build. Mater. 2009, 23, 837-845. [CrossRef]

40. Sbartaï, Z.M.; Laurens, S.; Elachachi, S.M.; Payan, C. Concrete properties evaluation by statistical fusion of NDT techniques. Constr. Build. Mater. 2012, 37, 943-950. [CrossRef]

41. Ploix, M.A.; Garnier, V.; Breysse, D.; Moysan, J. NDE data fusion to improve the evaluation of concrete structures. NDT E Int. 2011, 44, 442-448. [CrossRef]

42. Villain, G.; Sbartaï, Z.M.; Dérobert, X.; Garnier, V.; Balayssac, J.P. Durability diagnosis of a concrete structure in a tidal zone by combining NDT methods: Laboratory tests and case study. Constr. Build. Mater. 2012, 37, 893-903. [CrossRef]

43. Völker, C.; Shokouhi, P. Multi sensor data fusion approach for automatic honeycomb detection in concrete. NDT E Int. 2015, 71, 54-60. [CrossRef]

44. Dérobert, X.; Lataste, J.F.; Balayssac, J.P.; Laurens, S. Evaluation of chloride contamination in concrete using electromagnetic non-destructive testing methods. NDT E Int. 2017, 89, 19-29. [CrossRef]

45. Hugenschmidt, J.; Mastrangelo, R. GPR inspection of concrete bridges. Cem. Concr. Compos. 2006, 28, 384-392. [CrossRef]

46. Maierhofer, C. Nondestructive evaluation of concrete infrastructure with ground penetrating radar. J. Mater. Civ. Eng. 2003, 15, 287-297. [CrossRef]

47. Morris, I.; Abdel-Jaber, H.; Glisic, B. Quantitative attribute analyses with ground penetrating radar for infrastructure assessments and structural health monitoring. Sensors 2019, 19, 1637. [CrossRef]

48. Jazayeri, S.; Kruse, S.; Hasan, I.; Yazdani, N. Reinforced concrete mapping using full-waveform inversion of GPR data. Constr. Build. Mater. 2019, 229, 117102. [CrossRef]

49. Clemena, G.G.; Sprinkel, M.M.; Long, R.R., Jr. Use of Ground-Penetrating Radar for Detecting Voids under a Jointed Concrete Pavement; Transportation Research Record: Washington, DC, USA, 1987.

50. Anderson, N.L.; Ismael, A.M.; Thitimakorn, T. Ground-penetrating radar: A tool for monitoring bridge scour. Environ. Eng. Geosci. 2007, 13, 1-10. [CrossRef]

51. Laurens, S.; Balayssac, J.; Rhazi, J.; Klysz, G.; Arliguie, G. Non-destructive evaluation of concrete moisture by GPR: Experimental study and direct modeling. Mater. Struct. 2005, 38, 827-832. [CrossRef]

52. Dérobert, X.; Iaquinta, J.; Klysz, G.; Balayssac, J.P. Use of capacitive and GPR techniques for the non-destructive evaluation of cover concrete. NDT E Int. 2008, 41, 44-52. [CrossRef]

53. Plati, C.; Loizos, A. Estimation of in-situ density and moisture content in HMA pavements based on GPR trace reflection amplitude using different frequencies. J. Appl. Geophys. 2013, 97, 3-10. [CrossRef]

54. Morris, I.M.; Kumar, V.; Glisic, B. Predicting material properties of concrete from ground-penetrating radar attributes. Struct. Health Monit. 2020, 1475921720976999.

55. Rodés, J.P.; Pérez-Gracia, V.; Martínez-Reguero, A. Evaluation of the GPR frequency spectra in asphalt pavement assessment. Constr. Build. Mater. 2015, 96, 181-188. [CrossRef]

56. Sigurdardottir, D.H. Strain-Based Monitoring Methods for Beam-Like Structures. Ph.D. Thesis, Princeton University, Princeton, NJ, USA, 2015. 
57. Morris, I.M.; Abdel-Jaber, H.; Glisic, B. Ground penetrating radar as a monitoring tool: Mapping internal features with attribute analysis. In Proceedings of the SHMII 8, Brisbane, Australia, 5-8 December 2017.

58. Allroggen, N.; Tronicke, J. Attribute-based analysis of time-lapse ground-penetrating radar data. Geophysics 2016, 81, H1-H8. [CrossRef]

59. Annan, A. Ground Penetrating Radar Principles, Procedures, and Applications; Sensors and Software Inc.: Mississauga, ON, Canada, 2003; p. 285.

60. Allen, R. Automatic earthquake recognition and timing from single traces. Bull. Seismol. Soc. Am. 1978, 68, 1521-1531.

61. Wong, P.T.; Lai, W.W.; Sham, J.F.; sun Poon, C. Hybrid non-destructive evaluation methods for characterizing chloride-induced corrosion in concrete. NDT E Int. 2019, 107. [CrossRef]

62. Breiman, L. Random forests. Mach. Learn. 2001, 45, 5-32. [CrossRef]

63. Kohavi, R. A study of cross-validation and bootstrap for accuracy estimation and model selection. In Proceedings of the IJCAI, Montreal, QC, Canada, 20-25 August 1995; Volume 14, pp. 1137-1145.

64. Rubin, L.; Witkiewitz, K.; Andre, J.; Reilly, S. Methods for handling missing data in the behavioral neurosciences: Don't throw the baby rat out with the bath water. J. Undergrad. Neurosci. Educ. 2007, 5, A71. [PubMed]

65. Bergstra, J.; Bengio, Y. Random search for hyper-parameter optimization. J. Mach. Learn. Res. 2012, 13, $281-305$.

66. C1074-19e1. Standard Practice for Estimating Concrete Strength by the Maturity Method; ASTM International: West Conshohocken, PA, USA, 2019.

67. Plowman, J.M. Maturity and the strength of concrete. Mag. Concr. Res. 1956, 8, 13-22. [CrossRef]

68. Carino, N.J. The Maturity Method. In Handbook on Nondestructive Testing of Concrete; Malhotra, V.M., Carino, N.J., Eds.; CRC Press: West Conshohocken, PA, USA, 2003; pp. 5.1-5.47.

69. Ruxton, G.D. The unequal variance t-test is an underused alternative to Student's t-test and the Mann-Whitney U test. Behav. Ecol. 2006, 17, 688-690. [CrossRef]

70. Past Weather in Princeton, NJ, USA. Available online: https://www.timeanddate.com/weather/@5102922/historic (accessed on 24 April 2021).

71. Morris, I.M.; Kumar, V.; Lopez, S.A.; Glisic, B. Comparing predicted in situ 8-year concrete strength by ground penetrating radar attributes and maturity method. In Nondestructive Characterization and Monitoring of Advanced Materials, Aerospace, Civil Infrastructure, and Transportation XV; Yu, T.Y., Gyekenyesi, A.L., Eds.; International Society for Optics and Photonics, SPIE: Bellingham, WA, USA, 2021; Volume 11592, pp. 38-47. [CrossRef] 